\title{
Introduction to Energy Strategy Reviews theme issue "Future Energy Systems and Market Integration of Wind Power"
}

Energy Strategy Reviews (ESR) provides a peer-reviewed publication platform to evaluate strategy options for tomorrow's energy systems. The focus in this special issue is on "Future Energy Systems and Market Integration of Wind Power" and possible solutions are highlighted from the strategy viewpoint while addressing key technology components. One of today's important challenges is to design and integrate wind power into existing energy supply systems. Solutions must ensure a smooth energy transition by seamless technology integration and flexible market access.

\section{Theme issue focus}

Wind power is expected to play an important role in future sustainable energy systems around the world. The challenges of integrating such fluctuating and intermittent resources are well known and have been widely discussed. Solutions for the future are based on today's technology designs and market structures. Often a focus is taken solely on electricity supply and solutions such as electricity storage and flexible electricity demands are suggested and analysed. However, the challenge is to develop wind power into cost-effective energy solutions and ensure an optimum system integration of wind power into future energy systems and markets. This special issue of ESR includes: an original energy vision, a collection of analyses, and case studies on wind power and its interrelated systems.

\section{Energy Vision}

As in earlier issues, ESR opens this issue with an Energy Vision, featuring a prominent energy leader who presents a visionary statement on our future energy systems. Mr Christian Kjar, CEO of the European Wind Energy Association (EWEA) describes his vision of the transition towards sustainable energy systems. He argues these will generate not only wealth but also contribute to lasting peace by reducing global energy tensions. Nations are unlikely to go to war over renewable energy resources as they substitute energy imports with domestic employment and technology exports. As Mr Kjar argues, this is an opportunity for energy dependent nations to change from being fossil fuel importers to becoming renewable energy technology exporters while mitigating the devastating effects of climate change. However, to deploy renewable energy most effectively and cost-efficiently, politicians and decision-makers need to urgently overcome the technological and political inertia in the world's energy markets which continues to block the transition to a more economically optimal and resource efficient energy future.

\section{Energy Analyses}

The analysis section of this special issue features three papers. The first paper, authored by an interdisciplinary group of 12 researchers and energy experts from five Danish universities and companies, evaluates the history and advances in the large-scale integration of wind power into the electricity supply and market systems of Denmark, which is one of the front runners. Denmark has more than a decade of experience with a wind power share equal to around 20 percent of its electricity demand. Since Denmark has strong transmission interconnectors to neighbouring countries, the question is if the large-scale integration has been possible only due to large exports of electricity in hours of excess wind production or if it could and should be implemented in other regions as well? Furthermore, how much did it cost Danish taxpayers and what are the benefits to electricity consumers? The study argues that such information cannot be found in simple time correlations. A market model is developed to identify causal relationships and applied to the year 2008. It reaches the conclusion that only about 1 percent of Danish wind power was exported, which means nearly all of the generated wind power was used to meet the domestic demand. In recent years, existing Danish wind power has been financed not by taxpayers but solely by electricity consumers. The paper presents a methodology to identify the influence on consumer prices based on historic performance data (2004-2008). While maintaining electricity production prices below the EU average, the net influence of wind power has been as low as 1-3 percent of the consumer price over the period studied.

In the next paper by Patrick Sullivan and a group of researchers from the National Renewable Energy Laboratory (USA) together with the International Institute for Applied Systems Analysis (Austria), the Danish case is lifted to the global level and a global integrated assessment model for electric sector reliability is introduced and applied to scenarios with greenhouse gas (GHG) limits. The paper emphasises how renewable energy technologies such as wind power interact with the electricity grid differently than conventional power generation technologies. As a result, renewable solutions require adjustments in investments and generation decisions. The paper estimates the expected development in global wind electricity generation under different greenhouse gas restrictions. It illustrates how applying a stringent GHG constraint consistent with keeping $\mathrm{CO}_{2}$ equivalent concentration below $450 \mathrm{ppm}$ in 2100 would dramatically change the economics of the energy system and among other things make wind power more economically competitive with fossil fuel.

In the third analysis paper, a group of researchers from Aalborg University (Denmark) led by Frede Hvelplund argue that $\mathrm{CO}_{2}$ constraints have not been effectively 
implemented in the current energy markets on the contrary: the further development of wind turbine power is facing a number of fundamental economic and institutional barriers. The investment costs have increased due to a lack of good locations for new turbines at the same time as the market value is decreasing due to integration problems arising from the variability challenge. The paper makes use of merit of order supply and demand diagrams to illustrate and understand the principle bottlenecks, it defines 4 specific target barriers and makes proposals on how to overcome them. One of the main conclusions in this study is that least-cost implementation strategies and achieving suitable electricity market designs require an overall smart energy systems approach rather than a sole focus on electricity. Moreover, the paper emphasises the importance of local ownership and support for onshore turbine locations.

\section{Case studies}

The case studies section of this special issue includes a number of key contributions. David Elliott presents an essay on the emergence of supergrids by exploring the strategic and political pros and cons of using such a technology to link up and balance the large renewable resource potential that exists in and around the EU. However, as pointed out in the paper such considerations may also apply to e.g. USA and China. One of the conclusions is that further investigations are needed, especially on the opportunity costs, e.g. would storage or local solutions be less expensive and are there more effective ways to balance variable demand and supply?
Following up on this question, an interdisciplinary group of electricity market experts led by Peter Sorknces and co-workers quantify how the wind turbines themselves can play a more active role in balancing electricity supply and demand. The paper analyses whether wind turbines in the future should participate not only in the day-ahead wholesale market but also play an active role in the real-time balancing of market supply and demand. It is found that wind turbines are able to play an active role in downward regulation and thereby increase profits.

The barriers to implementing investment intensive projects such as renewable energy and electricity grid infrastructures are especially high in the emerging economies. Benjamin Sovacool points to the need to mobilise financial resources for renewable energy. He shows how market access can be expanded by the implementation of pro-poor public-private partnerships. These are needed because in most of the cases he assessed in his groundbreaking study, government investment and public budgets have proven to be insufficient incentives.

Two more case studies show that emerging economies are making headway with new power generation solutions: Parimal Acherjee presents the current power supply system of India and prospective future energy options are discussed. The potential effects of smart grids on the social, economic and power sectors are outlined. Principal obstacles for the implementation of smart grids in India are highlighted, including a possible framework for the smart grid architecture. Recent initiatives taken by the government of India related to smart grids are reviewed and the study suggests a strategy for implementing smart grids in India. Another case study by Monjour Mourshed, based on a case from Bangladesh, shows how an increasing oilbased generation capacity does not always result in a decrease in blackouts - on the contrary: increasing dependence on volatile international energy markets puts macroeconomic stress on the country. This issue of ESR concludes with a final case study on the reality of non-renewable energy. A team led by Stefano Casertano outlines how oil companies have accelerated their exploration efforts to locate new oil and gas resources to continue filling the glaring gap between renewable energy supply and total energy demand.

We think this third issue of Energy Strategy Reviews puts forward some highly relevant research contributions to the further development of future energy systems and market integration of wind power. We hope you will enjoy the reading.

\section{Acknowledgement}

Numerous people helped putting together this issue. We particularly thank for valuable input and support, Pernille Sylvest Andersen and Mette Reiche Sørensen, both at Aalborg University. Woodrow Clark (Clark Strategic Partners) contributed to the early stages of the review process for this issue, for which he is gratefully acknowledged.

Henrik Lund, Guest Editor Aalborg University, Denmark

Ruud Weijermars, Editor-in-Chief Delft University of Technology, The Netherlands

Available online 12 February 2013 